\title{
Geographically weighted regression for modelling the accessibility to the public hospital network in Concepción Metropolitan Area, Chile
}

\author{
Marcela Martínez Bascuñán, ${ }^{1}$ Carolina Rojas Quezada ${ }^{1,2}$ \\ ${ }^{1}$ Centre for Urban Sustainable Development, University of Concepción; ${ }^{2}$ Department of \\ Geography, University of Concepción, Concepción, Chile
}

\begin{abstract}
Accessibility models in transport geography based on geographic information systems have proven to be an effective method in determining spatial inequalities associated with public health. This work aims to model the spatial accessibility from populated areas within the Concepción metropolitan area (CMA), the second largest city in Chile. The city's public hospital network is taken into consideration with special reference to socio-regional inequalities. The use of geographically weighted regression (GWR) and ordinary least squares (OLS) for modelling accessibility with socioeconomic and transport variables is proposed. The explanatory variables investigated are: illiterate population, rural housing, alternative housing, homes with a motorised vehicle, public transport routes, and connectivity. Our results identify that approximately $4.1 \%$ of the population have unfavourable or very unfavourable accessibility to public hospitals, which correspond to rural areas located south of CMA. Application of a local GWR model $\left(0.87 \mathrm{R}^{2}\right.$ adjusted) helped to improve the settings over the use of traditional OLS methods (multiple regression) $\left(0.67 \mathrm{R}^{2}\right.$ adjusted) and to find the spatial distribution of both coefficients of the explanatory vari-
\end{abstract}

Correspondence: Carolina Rojas Quezada, Department of Geography, University of Concepción, Calle Victoria S/N, Barrio Universitario Concepción, Chile.

Tel. +56.041 .2203233 - Fax: +56.041 .2207396$

E-mail: crojasq@udec.cl

Key words: Accessibility; Spatial equity; Hospital facility; Geographically weighted regression; Chile.

Acknowledgements: the following projects are thanked: FONDAP CONICYT 15110020 CEDEUS; GESITRAN Innova Biobío ibb-11-PCS2-1116; FONDECYT 1150239. Contributions of Ph.D. Juan Carrasco and Ph.D. Alejandro Tudela, University of Concepción, are also thanked.

Received for publication: 13 January 2016.

Revision received: 23 May 2016.

Accepted for publication: 24 May 2016.

(C) Copyright M.M. Bascuñán and C.R. Quezada, 2016

Licensee PAGEPress, Italy

Geospatial Health 2016; 11:451

doi:10.4081/gh.2016.451

This article is distributed under the terms of the Creative Commons Attribution Noncommercial License (CC BY-NC 4.0) which permits any noncommercial use, distribution, and reproduction in any medium, provided the original author(s) and source are credited. ables, demonstrating the local significance of the model. Thus, accessibility studies have enormous potential to contribute to the development of public health and transport policies in turn to achieve equality in spatial accessibility to specialised health care.

\section{Introduction}

In recent years, numerous studies using tools based on geographic information systems (GIS) have been carried out to assess the impact of accessibility on territorial imbalances of relevant aspects such as public health. This information provides important opportunities to assess the spatial distribution of hospital facilities and primary health care (Ramírez and Bosque Sendra, 2001; Schuurman et al., 2006; Sasaki et al., 2010; Buzai, 2011). These studies have also enabled the identification of served and/or non-served areas as well as of the beneficiary and/or deprived socio-spatial groups regarding accessibility (Fuenzalida, 2010).

In this context, geographical studies - developed in Latin America and carried out from a spatial and automated approach - generally focus on planning, location, and territorial management of health services. These studies have aimed to assess how the population is guaranteed equitable access to facilities, according to coverage areas, taking into account both primary and specialised care. The spatial expression of the health system implies, at the same time, an equitable geographical distribution of the centres providing health services to the population. However, the transportation system, which in the end enables the mobility of the population, has seldom been considered. Nevertheless, these studies show variation in accessibility levels. In this regard, Dewulf et al. (2013) evaluated the results of different GIS methods, which have the main problem of not capturing local, spatial variations. However, if cumulative opportunity measures are considered as an accessibility indicator, it is relevant to include the travel patterns and socio-demographic characteristics of the population (Páez et al., 2010).

In the Concepción metropolitan area (CMA), there are 228 localities (30 urban and 198 rural) distributed among different municipalities and census districts. Some localities possessing high population density do not have hospitals or primary health care centres. Many of these localities are more rural than city-like and the roads are generally poor, preventing proper connectivity with the urban areas where health care infrastructure is located. Considering these aspects, as well as the socio-economic characteristics and material circumstances of the population treated in public hospitals, it is important to model the accessibility to these facilities in CMA in order to determine the existing inequalities in the territory. Hence, our study represents a contribution to the search for alternatives that can solve this accessibility problem. 
The aim of this work is to model the spatial accessibility of the populated urban and rural settlements of CMA to the public health care system considering the transportation network as the cornerstone enabling accessibility from the localities and spatial variations. Overall, our study has the purpose of identifying and analysing social and territorial imbalances.

\section{Materials and Methods}

\section{Study area}

CMA is composed of 11 municipalities that house a total population of 966,411 residents (INE, 2002). The majority of the population is concentrated in Concepción and Talcahuano, and these cities are highlighted as the principal urban articulators in this industrial area of the metropolitan territory. The 11 municipalities are comprised of 121 central districts and 228 localities (Figure 1). In this study, 119 census districts of CMA were considered, excluding the districts corresponding to Quiriquina (Talcahuano) and Santa María (Coronel) islands. The explanatory variables investigated were captured based on that territorial unit.

The geographic unit that subdivides the municipalities is the census district, which was chosen for this study as it incorporates characteristics of the population, homes, and dwellings in both urban and rural areas with a number of spatial units appropriate for modelling at the local level. Furthermore, the territory in which human settlements are located constitutes what is called a locality in terms of the census. According to the population numbers and the type of predominant economic activity, localities are classified as urban or rural. In CMA, it is possible to find one or more localities per district that provide levels that are particularly representative of travel times and therefore serve the purpose of calculating accessibility. Thus, the main point is considering the location of the settlement but not centroid of the district, which in many cases does not adequately describe population distribution (Figure 1).

\section{Data}

We used the road network to compute the shortest travel times from localities to hospitals. To model the road network, the functionalities of topology of ArcGIS (ESRI, Redlands, CA, USA) were used. The state, concession and urban highways of the municipality that are part of CMA were included at a 1:10,000 scale, updated to the year 2013 by the Ministry of Housing and Urban Planning. The road data has basic characteristics such as: measure of length for each section, speed limit, and type of road. Localities are represented by a georeferenced element (point) and the census districts as polygons, both obtained from the GIS Database of the National Statistical Institute of Chile (INE, 2002).
Before applying regression methods to model accessibility, a correlation analysis was performed among the set of candidate explanatory variables. In correspondence to Bocco et al. (2000) and Rojas et al. (2013), values with correlations larger than 0.8 were discarded in order to avoid possible problems with multicollinearity. In this study these values were found for occupation (positive correlation with homes with a vehicle), ethnicity (positive correlation with illiterate population) and housing with deficient sanitary services (positive correlation with alternative housing). The analysis of Pearson s bivariate correlations (Bollen and Barb, 1981) is presented with the variables that showed correlations below 0.8 and therefore chosen for the modelling (Table 1). Moran's I (Fotheringham et al., 2002; Patel and Waters, 2012) was applied to the six explanatory variables in order to verify the presence or absence of the spatial autocorrelation in its distributions. Results showed that for all the variables, Moran's I suggested a spatial autocorrelation that was statistically significant with a clustered distribution (Table 2). Thus, both the $\mathrm{Z}$ score and $\mathrm{P}$ value indicate rejection of the null hypothesis (which establishes that the entity values are distributed randomly in the studied area).

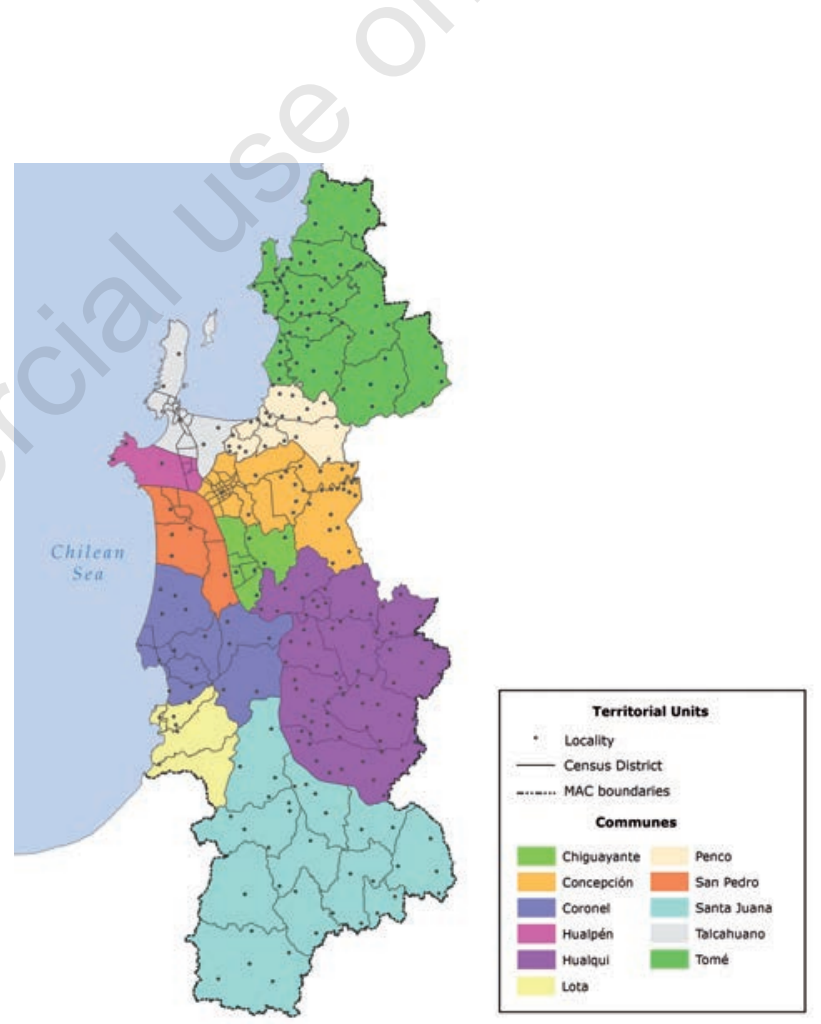

Figure 1. Concepción metropolitan study area with locality, census district and municipality boundaries.

Table 1. Bivariate correlations between explanatory variables.

\begin{tabular}{|c|c|c|c|c|c|c|}
\hline & $\begin{array}{l}\text { Public transport } \\
\text { routes }\end{array}$ & Connectivity & $\begin{array}{c}\text { Homes with a } \\
\text { vehicle }\end{array}$ & Rural housing & $\begin{array}{c}\text { Alternative } \\
\text { housing }\end{array}$ & $\begin{array}{l}\text { Illiterate } \\
\text { population }\end{array}$ \\
\hline Public transport routes & 1 & & & & & \\
\hline Connectivity & 0.666 & 1 & & & & \\
\hline Homes with a vehicle & 0.343 & 0.215 & 1 & & & \\
\hline Rural housing & -0.483 & -0.530 & -0.293 & 1 & & \\
\hline Alternative housing & 0.215 & 0.160 & -0.072 & 0.002 & 1 & \\
\hline Illiterate population & 0.114 & 0.085 & -0.062 & 0.024 & 0.587 & 1 \\
\hline
\end{tabular}


In order to model public health care accessibility, six potentially explanatory socio-economic and transportation variables were used. Four variables were chosen from the 2002 National Population and Housing Census with reference to the hierarchies of People, Housing, and Homes (INE, 2002), while two were obtained from the Gesitran Biobio project (www.gesitranbiobio.cl), related to the Transportation hierarchy (number of public transport routes and connectivity index). Table 3 presents the list of variables and their descriptions.

Extraction of the census variables was carried out with the free software developed by CEPAL, REDATAM R+SP Process (CEPAL, Santiago de Chile, Chile; Fuenzalida et al., 2014; Villanueba, 2010). This programme is capable of processing census data, and was used for the 2002 data mentioned earlier. Also, information can be disaggregated into different geographic units.

\section{Accessibility modelling method}

Network Analyst, a package extension included in ArcGIS (ESRI), was used to calculate minimal routes between localities and hospitals in order to obtain origin-destination travel time matrices. The calculation of accessibility was based on the average of impedances that separate each locality from the hospital centres through the network where the number of hospitals of destination had been previously assigned according to the municipality to which they belong. Therefore, in this research, accessibility should be understood as the average travel time from each locality to its assigned hospital.

The hospital network of CMA's health system is comprised of seven establishments belonging to the public health services of Concepción (CPHS) and those belonging to Talcahuano (TPHS). The municipali-

Table 2. Spatial autocorrelation for explanatory variables.

\begin{tabular}{lcccc} 
Variable & Moran's I & Pattern & Z-score $^{*}$ \\
Public transport routes & 0.502 & Clustered & 12.346 & 16.728 \\
Connectivity & 0.687 & Clustered & 5.231 & 0.000 \\
\hline Homes with a vehicle & 0.201 & Clustered & 8.631 & 0.000 \\
Rural housing & 0.342 & Clustered & 11.369 & 0.000 \\
Alternative housing & 0.511 & Clustered & 6.385 & 0.000 \\
Illiterate population & 0.454 & Clustered & 0.000 \\
\hline
\end{tabular}

*Measure of standard deviation; ${ }^{\circ}$ the probability of obtaining an observed pattern. $\mathrm{P}<0.05$

Table 3. Explanatory variables selected for the regression models.

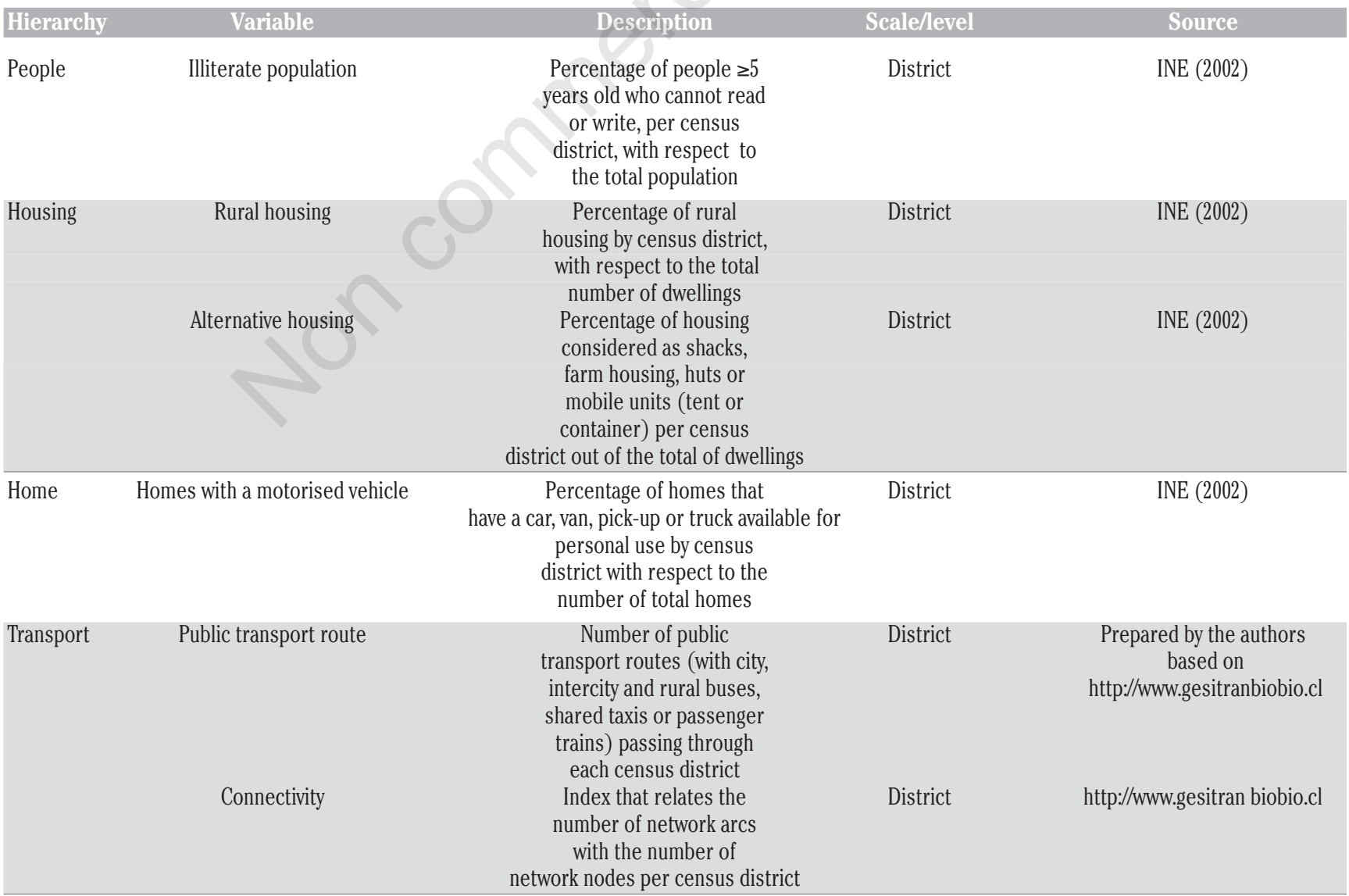


ties found within CPHS are Concepción, Chiguayante, Hualqui, San Pedro de la Paz, Coronel, and Lota. TPHS has centres in the cities of Talcahuano, Hualpén, Penco, and Tomé. It is important to note that the CMA population can only be assigned to one hospital (called the main or the primary hospital), while localities do not have this facility in their municipality. Localities assigned to two hospitals can either access the establishment placed in their municipality of origin or their main hospital (Regional Hospital- Higueras Hospital) as shown in Figure 2.

Taking the localities as a unit of origin, an aggregation of values was done considering the average travel times from these localities to the district level for their incorporation as a dependent variable in the modelling. The travel times were integrated into diverse studies in order to model accessibility to primary health care centres/hospitals (Brabyn and Skelly, 2001; Hare and Barcus, 2007; Bagheri et al., 2009; Rodríguez, 2010; Munoz and Kallestal, 2012), where the location factor (population, health care centres) and the characteristics of the network were considered in order to obtain the travel time factor (speed and length of the road sections).

\section{Spatial regression methods}

The accessibility was analysed as a variable dependent on ordinary least squares (OLS) according to Gutiérrez et al. (2012), and on geographically weighted regression (GWR) according to Fotheringham $e t$ al. (2002). The former is a global method based on the use of only one equation to explore the relationship between variables. In this model, it is assumed that the relationship is consistent throughout the whole study area (stationary), without considering the possibility that local variations exist due to the heterogeneity of the space. The latter is a local regression model that creates an equation for each element of the dependent variable data set, in order to capture geographic variations.

Global regression (OLS) can be represented by the equation (1):

$$
\gamma=\beta_{0}+\sum_{k} \beta_{k} x_{i k}+\varepsilon_{i}
$$

where $y$ is the estimated value of the dependent variable for the observation $i, \beta_{0}$ the intercept, $\beta_{k}$ the estimated parameter for the variable $k$, $x_{i k}$ the value of the variable $k t h$ for $i$, and $\varepsilon_{i}$ the error term (Fotheringham and Charlton, 1998).

The OLS approach calibrates a unique regression equation for all of the observations, while the GWR constructs a regression equation separately for each observation, where each equation is calibrated using a different weighting of the observations in the dataset. The GWR model, represented by equation (2), allowed us to work with local parameters instead of global parameters, i.e:

$$
\gamma=\beta_{0}\left(\mu_{i}, v_{i}\right)+\sum_{k} \beta_{k}\left(\mu_{i}, v_{i}\right) x_{i k}+\varepsilon_{i}
$$

where $u_{i}$ and $v_{i}$ indicate the point coordinates of ith in space (Fotheringham et al., 2002). Regarding the assignment of the weight of the GWR model, a weighting scheme known as the adaptive Kernel method (with spatial variation) was used, which assigns larger density variation measures where the weighting points are disperse and minor ones where they are more concentrated (Rojas et al., 2013).

The differences in the use of a global statistic model and a local one such as the GWR are based mainly in the capacity of the latter to be spatialised and represented in a GIS environment with emphasis on the differences regarding space, local disaggregation of the local statistics, among others (Fotheringham et al., 2002). Although the GWR model can be advantageous in order to distinguish heterogeneity of the space itself and it also makes it easier to go from a global perspective to a local analysis, thus obtaining a better grade of details and precision (Lloyd and Shuttleworth, 2005), it can also present reliability conflicts (Páez et al., 2011).

The calculations of the regression models (OLS and GWR) were implemented using the ArcGIS Modelling Spatial Relationships toolset. Multiple models were made using a set of candidate variables until selecting a model with high explanatory power and that incorporated the six explanatory variables that are relevant from the point of view of accessibility to healthcare.

\section{Results}

\section{Public hospital accessibility}

Figure 3 shows the geographic distribution pattern of the accessibility values that follow the typical centre-periphery model in which the city areas where hospital units are located show, most of the time, high levels of accessibility ( 0.9 to 24.2 minutes). Furthermore, surrounding areas record intermediate levels of accessibility (24.2 to 33.1 minutes), and areas located far from health care centres (in southern CMA) showed unfavourable, or very unfavourable, accessibility levels with an average of higher than 30 minutes (33.1 to 104.8 minutes). Most of these were rural areas. It is important to emphasise the optimal levels of access observed in the urban area of Concepción, Talcahuano, Hualpén, San Pedro de la Paz, and Penco (central conurbation), where most of the hospitals of the study area are concentrated (Regional

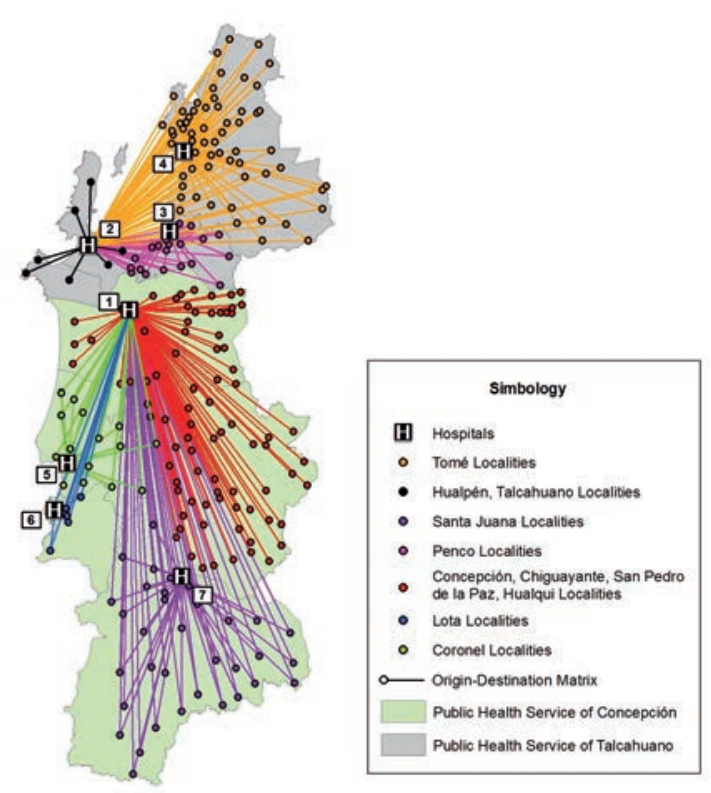

Figure 2. Hospital assignment matrix per locality. 1) Regional hospital; 2) Higueras hospital; 3) Penco-Lirquén hospital; 4) Tomé hospital; 5) Coronel hospital; 6) Lota hospital; 7) Santa Juana hospital. 
Table 4. Ordinary least squares model summary.

\begin{tabular}{lcccc} 
Variable & Coefficient & SE & P* & VIF $^{\circ}$ \\
Intercept & 60.183862 & 4.389099 & 0.000000 & - \\
Public transport routes & -0.067006 & 0.053620 & 0.084646 & 2.113207 \\
\hline Connectivity & -28.414235 & 3.535520 & 0.000000 & 2.515939 \\
Homes with a vehicle & -8.530927 & 3.765749 & 0.000179 & 1.218714 \\
\hline Rural housing & 43.943766 & 29.263301 & 0.321395 & 1.574576 \\
Alternative housing & 85.806702 & 30.530654 & 0.044428 & 1.679720 \\
\hline Illiterate population & 26.089914 & 15.744198 & 0.060757 & 1.560206 \\
\hline
\end{tabular}

$\mathrm{SE}$, standard error; $\mathrm{VIF}$, variance inflation factor. $* \mathrm{P}<0.05$; ${ }^{\circ}$ indicator of redundancy between the explanatory variables (when their values surpass the threshold of 7.5 ).

Hospital, Penco Hospital and Higueras Hospital). These areas also showed good urban connectivity from the point of view of the network topology. In this concentric area, average travel times to access hospital units ranged from 0.9 to 14.8 minutes.

In general, the variation in accessibility levels in CMA corresponds to the ease in arriving to a hospital, considering the network morphology as a useful aspect to identify infrastructure problems and, at the same time, the low speeds determined by the topology of the road. In these areas, as in the case of the localities belonging to Hualqui and Santa Juana, the predominant type of road is rural, which in some cases do not allow motorised transport. Therefore, in these cases, people have no alternative to walking.

\section{Ordinary least squares}

The OLS model summary (Table 4) shows that for a degree of confidence of $95 \%$, three out of the six explanatory variables are significant ( $\mathrm{P}$ value), corresponding to connectivity, homes with a vehicle, and alternative housing. All of these present the expected coefficients. The three variables that are not significant in the global model are likewise considered for the local model (GWR), with the aim of spatially evaluating the significance of their coefficients. Moreover, the variance inflation factor (VIF) values (all below the threshold of 7.5) indicate that there are no problems of multicollinearity among the explanatory variables.

Regarding the diagnostic model (Table 5), the global model fit (OLS) offers an adjusted $\mathrm{R}^{2} 0.67$, meaning that the variability in the travel times to hospitals can be explained with a precision of more than $60 \%$ with the six variables selected. The Jarque-Bera statistic (Jarque and Bera, 1987) implies a significant $P$ value, demonstrating that the regression residuals do not present a theoretical normal distribution. The Koenker statistic (BP) (Koenker, 1981) presents a statistically significant $P$ value, indicating that the relationship between explanatory and dependent variables is non-stationary (different in distinct spatial zones of the study area).

The decision to resort to spatial regression is justified when an improvement in the global fit is produced or when the presence of clusters is detected in the residual distribution that needs to be corrected (Gutiérrez et al., 2012). Considering these aspects, sufficient evidence exists to turn to GWR.

\section{Geographically weighted regression}

The adjusted $R^{2}$ in the GWR model was found to be 0.87 , a very important improvement with respect to the figure (0.67) delivered by the OLS model. In addition, the Akaike information criterion value (Hurvich $e t$ $a l ., 1998)$ is lower in GWR than OLS (845 and 941, respectively), and this parameter indicates a better performance for the local model.
Table 5. Ordinary least squares diagnostic model.

\begin{tabular}{lcc} 
Statistics & Diagnostic & P \\
Adjusted $\mathrm{R}^{2 \circ}$ & 0.677032 & - \\
AIC $^{\#}$ & 941.729 & - \\
\hline Jarque-Bera statistic $^{\S}$ & 135.512 & 0.000000 \\
BP statistic $^{\wedge}$ & 27.2450 & 0.000301
\end{tabular}

AIC, Akaike information criterion; BP, Koenker. ${ }^{\circ}$ Coefficient indicating the relative goodness of fit of the regression; "measure of the model value of adaption - the lower the value, the higher the model's performance; \$approach to establish if the residuals of a regression model are normally distributed; $\wedge$ approach testing the spatial variability of the variables.

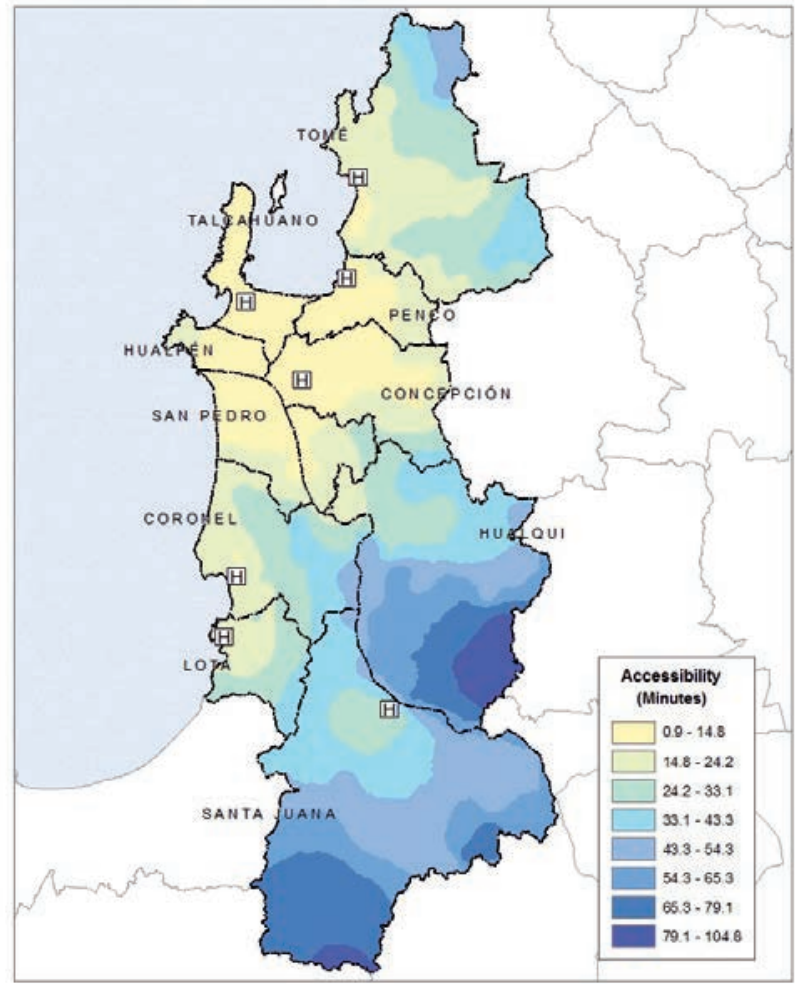

Figure 3. Accessibility to public hospitals in Concepción metropolitan area. 
Moreover, the residual analysis also shows better results in GWR than in OLS. As shown in Table 6, this improvement can be statistically verified. The calculated value of Moran's I for the residuals is much closer to the expected index in the GWR model by showing a lower variance and higher probabilities of random distribution ( $\mathrm{P}$ values and $\mathrm{Z}$ scores).

Moreover, the spatial distribution of the local adjustments produced with the GWR (local $R^{2}$ ) provided information regarding the spatial variation of the model's explanatory power. The distribution of the local $\mathrm{R}^{2}$ at the district level varied between 0.60 and 0.80 (Figure 4), demonstrating that the model has a better explanatory capacity in the central zone of CMA (districts belonging to municipalities of Concepción, Hualpén and Talcahuano), increasing the $\mathrm{R}^{2}$ above 0.73 .

This trend shows that the adjustment decreases in zones where there is a lower density of districts (southern CMA), so these zones have a lower number of neighbours. On the other hand, zones with higher density have more neighbours when adjusting the model (central zone), increasing the $\mathrm{R}^{2}$ above 0.71 . For the spatial variability analysis of the local coefficients of the explanatory variables (elasticity) in the GWR model, the spatial representation is shown from Figure 5 to 10 together with statistically significant $T$ values (measures the difference between an observed sample statistic and its hypothesised population parameter in units of standard error) at the $90 \%$ level, with T values higher than 1.64 and not significant in some census districts.

The variable regarding the public transport routes (Figure 5) showed significant values in southern CMA, including the municipalities of Santa Juana, Hualqui, Lota Coronel, part of San Pedro de la Paz, Chiguayante, and the rural area of Concepción, with high coefficients in the districts belonging to the municipality of Santa Juana ( -0.48 and -0.36 ), indicating a higher incidence of this variable in travel times.

Furthermore, the coefficients related to the variable of connectivity (Figure 6) are statistically significant in most of CMA, with the exception of the Península de Tumbes (Talcahuano), where the structural complexity of the road network does not significantly influence the travel times to hospitals. The relationship between the variable of connectivity and the travel times was found to be negative in all areas studied. The mean of the coefficients of this variable was -13.07 , but reached very high values in the South (Hualqui-Santa Juana) and in the North (Tomé) (-39.05 and -26.11, respectively) showing that travel time to the hospitals has an important effect.

The variable homes with a vehicle (Figure 7) showed a negative relationship with respect to the dependent variable. The highest coefficients varied between -15.4 and -4.8 . In this way, the highest/lowest number of homes with their own vehicle, in these zones, indicate a decrease/increase in travel time to hospitals. The coefficients that are statistically significant are present in the districts belonging to the municipalities of Tomé (northern CMA), in the rural areas of Concepción, Chiguayante, and San Pedro de la Paz (central zone), and in Hualqui, Coronel, and Lota (in the South). The districts belonging to Santa Juana (in the South) and the central conurbation of the territory did not provide evidence of statistically significant coefficients.

The variable related to rural housing (Figure 8) showed significant values in southern CMA, in the census districts belonging to the municipalities of Santa Juana, Lota, Coronel, Hualqui and CMA's central zone, specifically the municipalities of Talcahuano, Hualpén, and Penco. The highest coefficient values were observed in this area with a positive relationship influencing hospital travel times. In the districts in the eastern part of CMA where there was a change in the sign (negative relationship with respect to the dependent variable), the coefficients were not statistically significant (with the exception of five census districts belonging to Hualqui). Almost all of Concepción and Tomé presented statistically non-significant values.

With respect to alternative housing (Figure 9), statistically significant values were found in southern CMA (districts belonging to Hualqui, Concepción, Coronel, Lota, and Santa Juana) with especially high coefficients seen in the municipalities of Santa Juana and Hualqui (569.2-200.3, respectively). The coefficients indicate a positive relationship with the dependent variable in the districts where it was significant, showing that the presence of alternative housing in these zones is correlated with an increase in hospital travel times.

Finally, the illiterate population (Figure 10) showed its highest coefficients in southern CMA, i.e. the districts belonging to Santa Juana and Hualqui (98.7-288.3, respectively), where they are statistically significant. The same was also the case in the the census districts of Lota and other districts belonging to Coronel, Chiguayante, and Concepción. In these zones, the variable had a positive relationship with travel time to hospitals.

Table 6. Moran's $I$ in the residuals ordinary least squares and geographically weighted regression.

\begin{tabular}{lcc} 
Score & OLS & GWR \\
Moran's I & 0.251 & 0.019 \\
Expected index & -0.008 & -0.008 \\
\hline Variance & 0.001 & 0.000 \\
Z score & 6.372 & 0.933 \\
\hline Pvalue & 0.000 & 0.350 \\
Pattern & Clustered & Random \\
\hline
\end{tabular}

\section{OLS, ordinary least squares; GWR, geographically weighted regression.}

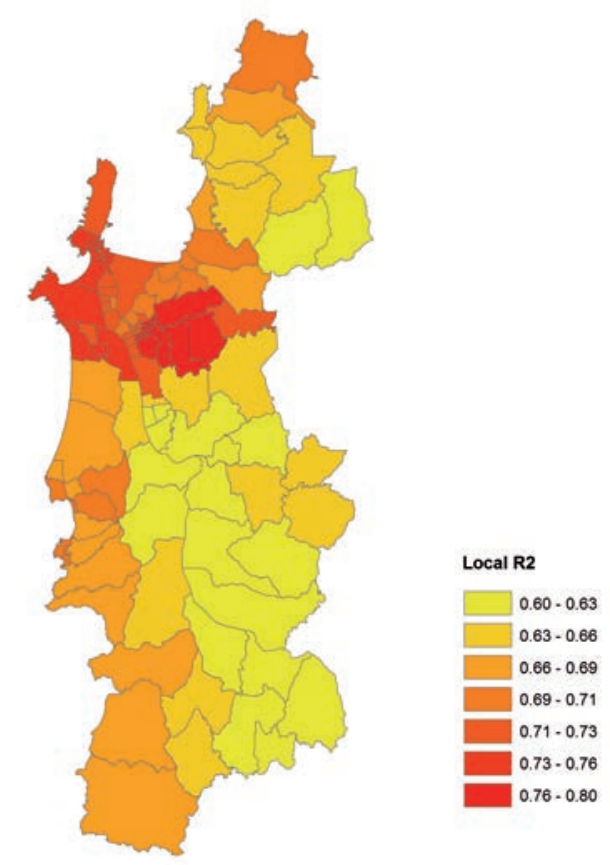

Figure 4. Spatial distribution of local $R^{2}$ in the geographically weighted regression model. 

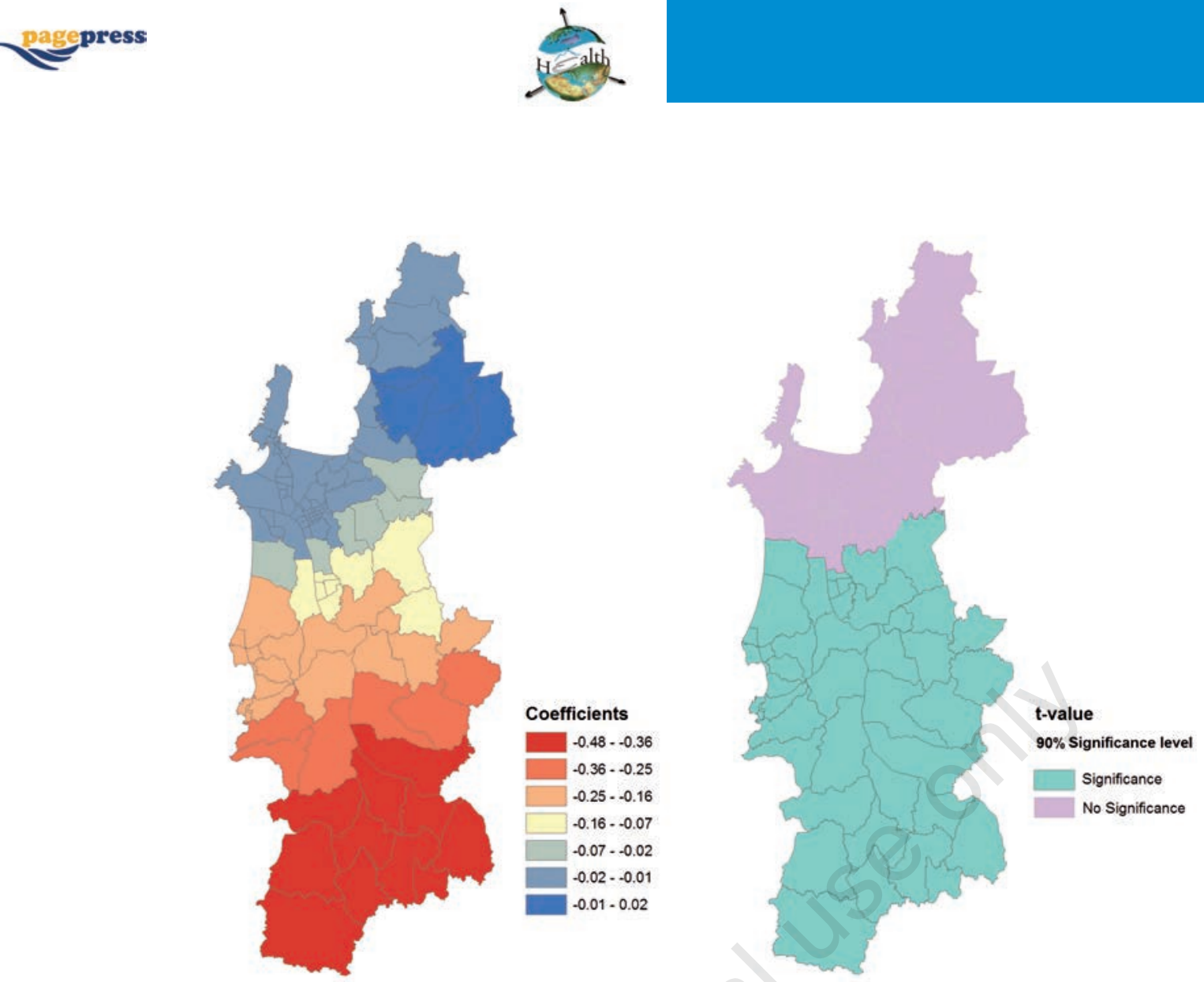

Figure 5. Public transport routes: spatial distribution of the local coefficients and $T$ values in the geographically weighted regression model.
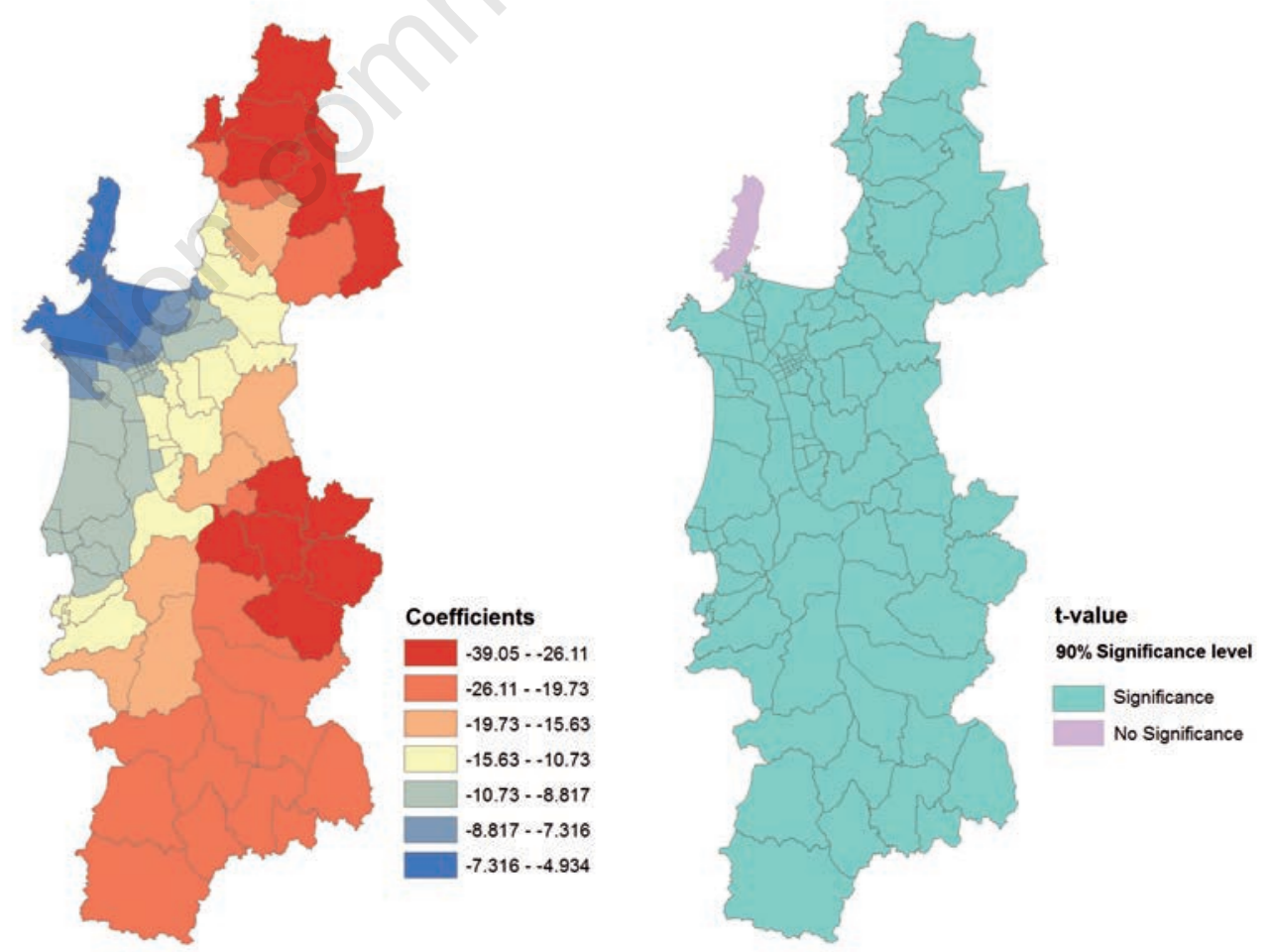

Figure 6. Connectivity: spatial distribution of the local coefficients and $\mathrm{T}$ values in the geographically weighted regression model. 


\section{Article}
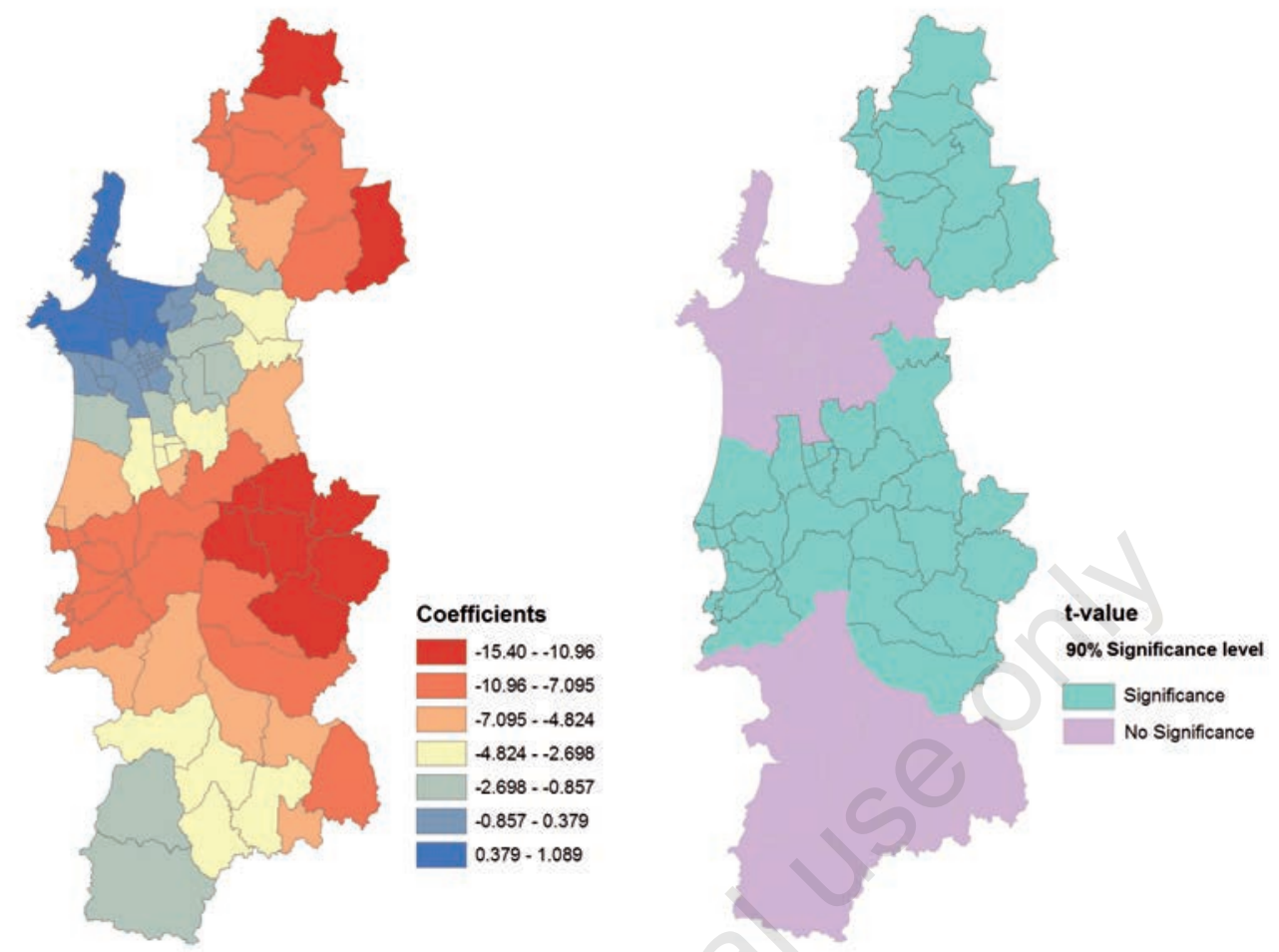

Figure 7. Homes with a vehicle: spatial distribution of the local coefficients and $T$ values in the geographically weighted regression model.
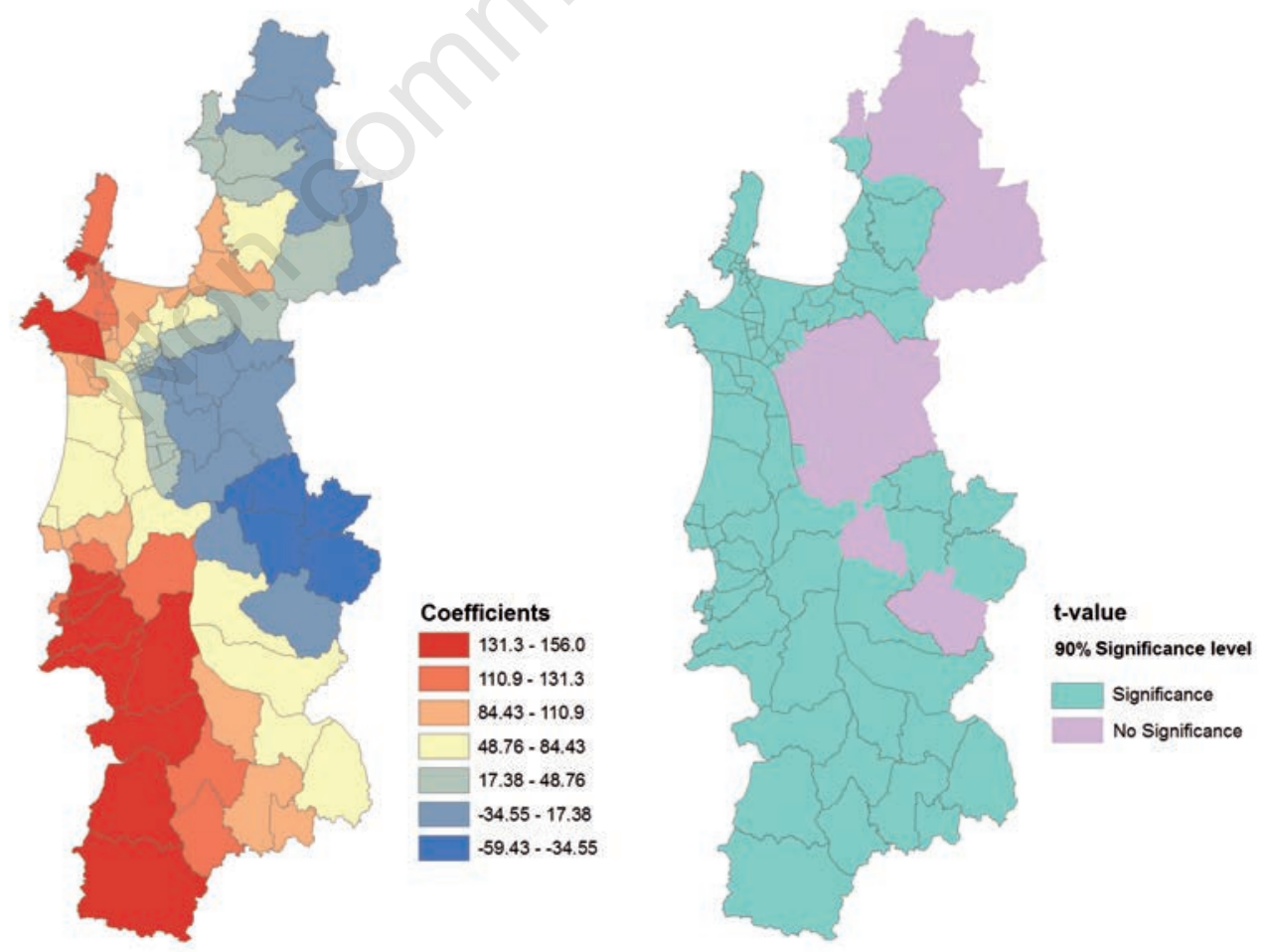

Figure 8. Rural housing: spatial distribution of the local coefficients and T values in the geographically weighted regression model. 

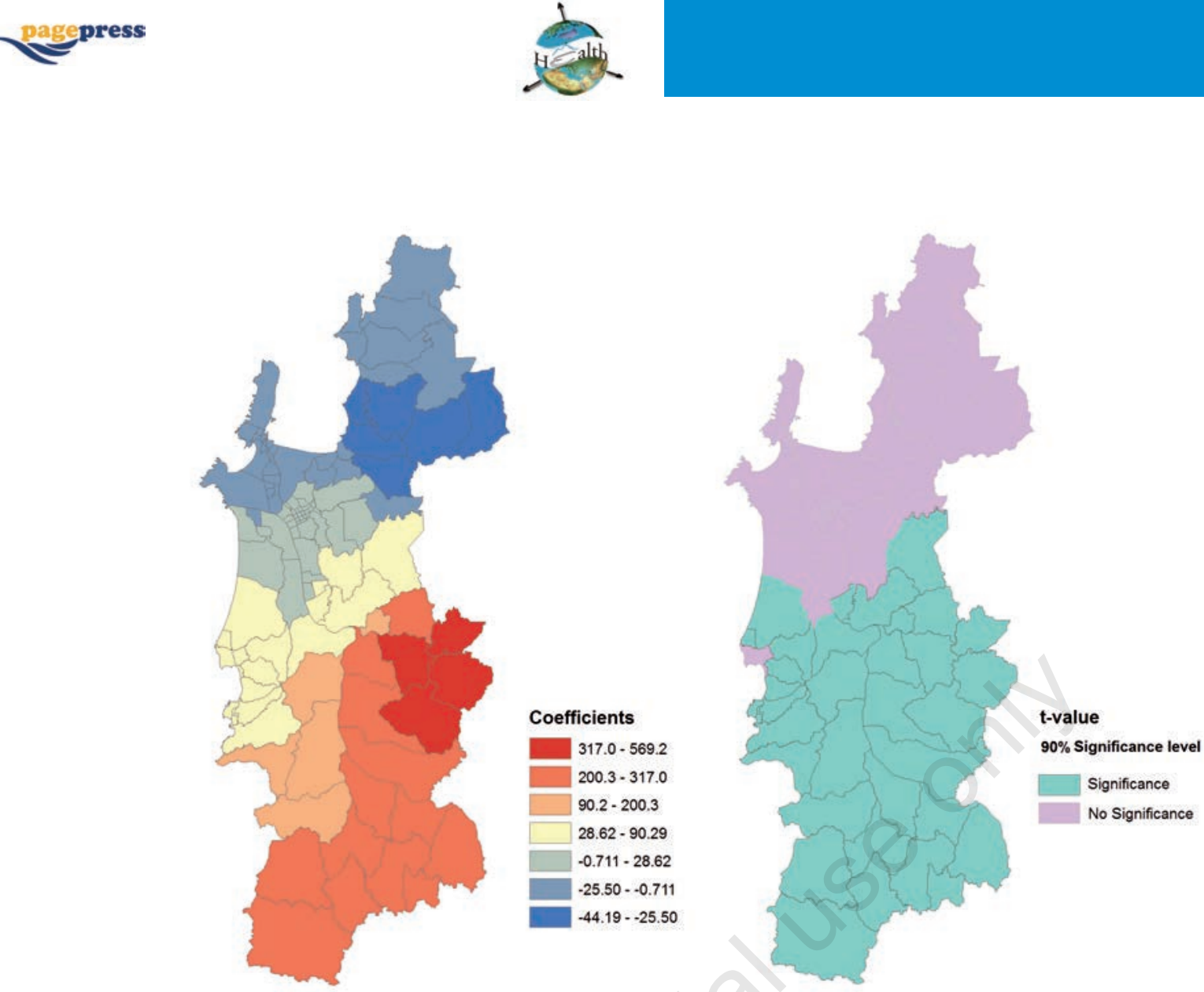

Figure 9. Alternative housing: spatial distribution of the local coefficients and $T$ values in the geographically weighted regression model.
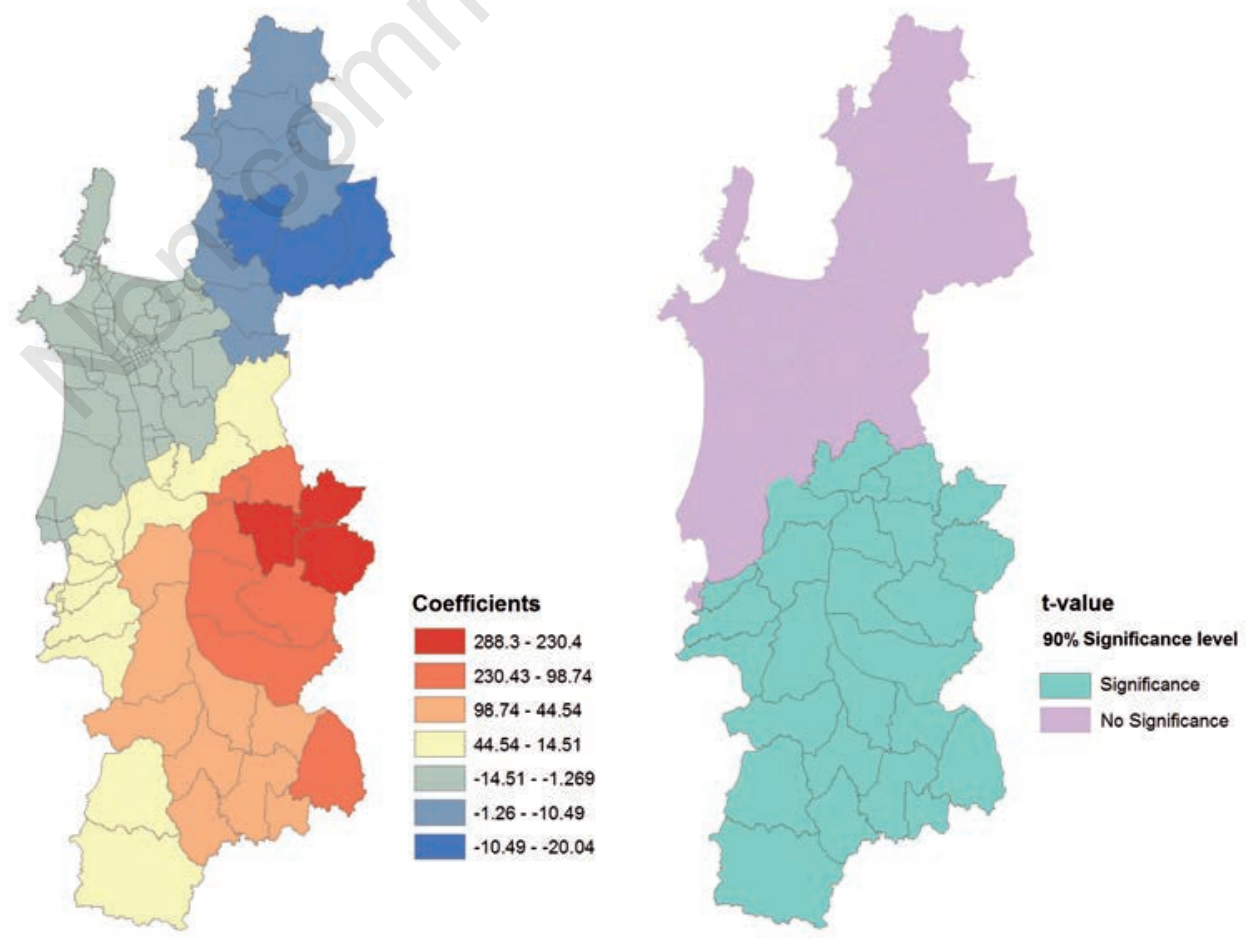

Figure 10. Illiterate population: spatial distribution of the local coefficients and $T$ values in the geographically weighted regression model. 


\section{Discussion}

This research found that approximately $4.1 \%$ of the population ( 37,228 people) living in the CMA $(900,000$ people) have unfavourable or very unfavourable access to public hospitals (travel times above 30 and 45 minutes, respectively). Of this population, $32.8 \%$ live in rural areas, especially in the municipalities of Tomé, Santa Juana, and Hualqui, where areas of particular low accessibility to hospitals were identified. In these locations, population has a strong need to increase its hospital accessibility, which is primarily due to long travel times.

The modelling of hospital accessibility using socio-economic and transportation variables elucidated local variations of the explanatory variables under study, some of which were found to have a strong influence on the hospital travel times in southern CMA. The relationship among the census variables of population, homes, and housing and the dependent variable suggests that, in general, the zones with shorter travel times to the hospital network centres showed better socio-economic characteristics when compared to those with longer ones. This aspect is in line with the results found by Bagheri et al. (2009) in the exploration of the local variation of the accessibility to primary health care based on a deprivation index in an GWR analysis. Likewise, Shah and Bell (2013) have published reports, where the advantages of this method are shown in the disaggregation of the relationships between socio demographic variables and the geographic accessibility to the primary health care services at the local scale.

The OLS model, on the other hand, showed that three out of the six variables were statistically significant. However, the results of the global regression are only averages of the total studied region and could conceal a large amount of interesting spatial variation in the relationships appearing in the local analysis (Bagheri et al., 2009). This becomes a problem when trying to understand how the relationships among variables change throughout the space investigated. Regarding this, the GWR model generates a local adjustment in multiple locations, repeating the process for all variables.

Regarding model performance, the OLS gives an adjusted $\mathrm{R}^{2}$ of 0.67 , while the GWR shows an adjusted $\mathrm{R}^{2}$ of 0.87 . Considering the six selected variables in this study, the variability of the travel times to hospitals can be explained with an accuracy of over $80 \%$, implying an important improvement with respect to the OLS model. The results identified the most deprived zones regarding spatial access to hospitals, and they also showed the highest coefficients of the selected variables.

As to the variables selected for this research, the socio-demographic characteristics based on the census used to analyse local health inequalities, focusing on the determinant needs of health care services, are increasingly used in health geography (Andersen et al., 2007; Chateau et al., 2012). For example, studies concerning social inequalities in healthcare have shown that for both sexes and all ages, the most deprived social classes have worse health indicators than the population belonging to more privileged social classes. The same has been shown for the poorest people or geographic areas and people or geographic zones with greater wealth (Benach and Amable, 2004). These aspects are clearly related to situations in our study areas in CMA.

It is important to note that one of the study limitations is that our research addresses accessibility to healthcare as a linear component of travel (relationship between an origin and a destination), and not from the perspective of the use and/or completion of health benefits. Therefore, the studies of mobility in health substitute this link to the relationship between a need (to receive attention in the public health system) and its satisfaction (to specify health benefits); the first approach is insufficient for this type of research, especially in the study of cases requiring prolonged medical treatment or periodic checks. In this sense, due to the marked inequality in Chile, further research is required from the perspective of geography and transportation.

\section{Conclusions}

Measuring the accessibility to health care establishments in a metropolitan area not only identifies areas of the territory with critical problems, but also strengthens the analysis regarding the inequality to accessing healthcare, an aspect difficult to assess with the classic geographic approach that uses accessibility to service or coverage by health care establishments with location as a single fundamental element. Modelling at the local scale shows many advantages over the global multiple regression model (Gutiérrez et al., 2012), as it provides information on areas of higher and lower adjustments, spatial relationship dynamics and their statistical significance. Indeed, we have shown the importance of considering local analysis in studies related to accessibility to health care, which should be understood as a means of overcoming the distance as an important instrument for determining existing inequalities in a territory. The geographic accessibility models have an enormous potential to contribute to policy development and to debate about the way to reach equality in accessibility to hospital establishments. Models are a critical resource that can be used by planners to give priority to the location and assignment of health services (Brabyn and Skelly, 2002). The application of geographic analysis procedures focused on solving empirical problems in the field of health geography is shown nowadays as a research area of great dynamism since its methodological procedures are supported by current GIS technology (Buzai, 2009).

\section{References}

Andersen R, Davidson P, Baumeister S, 2007. Improving access to care. In: Kominski GF, ed. Changing the US health care system: key issues in health services policy and management. pp 33-70. Wiley, Hoboken, NJ, USA.

Bagheri N, Holt A, Benwell G, 2009. Using geographically weighted regression to validate approaches for modelling accessibility to primary health care. Appl Spat Anal Policy 2:177-94.

Benach J, Amable M, 2004. [Las clases sociales y la pobreza]. [Article in Spanish]. Gac Sanit 18:16-23.

Bocco G, Mendoza M, Masera 0,2000. [La dinámica del cambio del uso del suelo en Michoacán. Una propuesta metodológica para el estudio de los procesos de deforestación]. [Document in Spanish]. Invest Geog 44:18-38.

Bollen KA, Barb KH, 1981. Pearson's $r$ and coarsely categorized measures. Am Sociological Review 46:232-9.

Brabyn L, Skelly C, 2001. Geographical access to services, health (GASH): modelling population access to New Zealand public hospitals. Available from: www.geocomputation.org/2001/papers/brabyn. pdf

Brabyn L, Skelly C, 2002. Modeling population access to New Zealand public hospitals. Int J Health Geogr 1:3.

Buzai GD, 2009. [Sistemas de información geográfica en geografía de la salud]. In: Buzai GD, ed. [Salud y enfermedad en geografía]. [Book in Spanish]. Lugar Editorial, Buenos Aires, Argentina, pp $111-34$.

Buzai GD, 2011. [Modelos de localización-asignación aplicados a servi- 
cios públicos urbanos: análisis espacial de Centros de Atención Primaria de Salud (CAPS) en la ciudad de Luján, Argentina]. [Article in Spanish]. Cuad Geogr 20:111-23.

Chateau D, Metge C, Prior H, Soodeen R, 2012. Learning from the census: the socio-economic factor index (SEFI) and health outcomes in Manitoba. Can J Public Health 8:23-7.

Dewulf B, Neutens T, De Weerdt Y, Van De Weghe N, 2013. Accessibility to primary health care in Belgium: an evaluation of policies awarding financial assistance in shortage areas. BMC Fam Pract 14:122.

Fotheringham AS, Brunsdon C, Charlton M, 2002. Geographically weighted regression: the analysis of spatially varying relationships. Wiley, Hoboken, NJ, USA.

Fotheringham AS, Charlton M, 1998. Geographically weighted regression: a natural evolution of the expansion method for spatial data analysis. Environ Plann A 30:1905-27.

Fuenzalida M, 2010. [Análisis de desigualdades territoriales en la oferta de equipamientos públicos: el caso de los hospitales en la red asistencial del sistema público de salud en Chile]. [Article in Spanish]. Geografía y Sistemas de Información Geográfica 2:11125.

Fuenzalida M, Guerrero R, Cobs V, 2014. [El uso de la técnica de autocorrelación espacial en la definición de los determinantes sociales de la salud del Área Metropolitana de Santiago de Chile]. [Article in Spanish]. In: Proceedings of the 16th National Congress of Technologies of Geographic Information, Alicante, Spain. Available from: rua.ua.es/dspace/bitstream/10045/46507/1/2014_Fuenzalida_ etal_Congreso_TIG.pdf

Gutiérrez J, García Palomares JC, Cardozo 0, 2012. [Regresión Geográficamente Ponderada (GWR) y estimación de la demanda de las estaciones del Metro de Madrid]. [Article in Spanish]. In: Proceedings of the 15th National Congress of Technologies of Geographic Information, Madrid, Spain.

Hare T, Barcus H, 2007. Geographical accessibility and Kentucky's heart-related hospital services. Appl Geogr 27:181-205.

Hurvich CM, Simonoff JS, Tsai C-L, 1998. Smoothing parameter selection in nonparametric regression using an improved Akaike information criterion. J Roy Stat Soc B 60:271-93.

INE, 2002. Population and Housing Census of Chile. Latin American Center of Demography (CELADE). National Statistical Institute of Chile, Santiago de Chile, Chile. Available from: http://espino.ine.cl/cgibin/RpWebEngine.exe/PortalAction?\&MODE $=$ MAIN\&BASE $=$ CPCHL2KREG\&MAIN=WebServerMain.inl

Jarque C, Bera A, 1987. A test for normality of observations and regression residuals. Int Stat Rev 163-72.

Koenker R, 1981. A note on studentizing a test for heteroscedasticity. J Econometrics 17:107-12.

Lloyd CD, Shuttleworth I, 2005. Analysing commuting using local regression techniques: scale, sensitivity, and geographical patterning. Environ Plann A 37:81-103.

Munoz U, Kallestal C, 2012. Geographical accessibility and spatial coverage modeling of the primary health care network in the Western Province of Rwanda. Int J Health Geogr 11:40.

Páez A, Farber S, Wheeler D, 2011. A simulation-based study of geographically weigthed regression as a method for investigating spatially varying relationships. Environ Plann A 43:2992-3010.

Páez A, Mercado RG, Farber S, Morency C, Roorda M, 2010. Accessibility to health care facilities in Montreal Island: an application of relative accessibility indicators from the perspective of senior and nonsenior residents. Int J Health Geogr 9:52.

Patel A, Waters N, 2012. Using geographic information systems for health research. In: Alam BM, ed. The geographic information system. In-Tech, Rijeka, Croatia, pp 303-20.

Ramírez M, Bosque Sendra J, 2001. [Localización de hospitales: analogías y diferencias del uso del modelo P-mediano en Sig raster y vectorial]. [Article in Spanish]. Ann Geogr Univ Complut 21:53.

Rodríguez V, 2010. [Medición de la accesibilidad geográfica de la población a la red de hospitales de alta resolución de Andalucía mediante sistemas de información geográfica]. In: Díaz-Delgado $R$, Pesquer L, Prat E, Bustamante J, Masó J, Pons J, eds. [Tecnologías de la información geográfica: la información geográfica al servicio de los ciudadanos]. [Book in Spanish]. University of Seville, Seville, Spain, pp 549-64.

Rojas C, Plata W, Valdebenito P, Muñiz I, De la Fuente H, 2013. [La dinámica de expansión urbana del area metropolitana de Concepción]. In: Williams J, Hidalgo R, Brand P, Pérez L, eds. [Metropolizaciones Colombia-Chile: experiencias de Bogotá, Medellín, Santiago y Concepción]. [Book in Spanish]. National University of Colombia, Bogotá, Colombia, pp 39-56.

Sasaki S, Comber A, Suzuki H, Brunsdon C, 2010. Using genetic algorithms to optimise current and future health planning-the example of ambulance locations. Int J Health Geogr 9:4.

Schuurman N, Fiedler R, Grzybowski S, Grund D, 2006. Defining rational hospital catchments for non-urban areas based on travel-time. Int $\mathrm{J}$ Health Geogr 5:43.

Shah TI, Bell S, 2013. Exploring the intra-urban variations in the relationship among geographic accessibility to $\mathrm{PHC}$ services and sociodemographic factors. Proceedings of the Second ACM SIGSPATIAL International Workshop on the Use of GIS in Public Health, 2013 November 05-08, Orlando, FL, USA, pp 68-76.

Villanueba A, 2010. [Accesibilidad geográfica a los sistemas de salud y educación. Análisis espacial de las localidades de Necochea y Quequén]. [Article in Spanish]. Revista Transporte y Territorio 2:136-57. 